\title{
Genome-Wide Analysis of Gene Regulatory Networks of the FVE-HDA6-FLD Complex in Arabidopsis
}

\author{
Chun-Wei Yu, Kao-Yuan Chang and Keqiang Wu* \\ Institute of Plant Biology, College of Life Science, National Taiwan University, Taipei, Taiwan
}

\section{OPEN ACCESS}

Edited by:

Dorothee Staiger.

Bielefeld University, Germany

Reviewed by:

Richard Amasino,

University of Wisconsin-Madison,

USA

Sebastian Marquardt,

Copenhagen University, Denmark

${ }^{*}$ Correspondence:

Keqiang Wu

kewu@ntu.edu.tw

Specialty section:

This article was submitted to Plant Genetics and Genomics,

a section of the journal

Frontiers in Plant Science

Received: 05 January 2016

Accepted: 11 April 2016

Published: 28 April 2016

Citation:

Yu C-W, Chang K-Y and Wu K (2016)

Genome-Wide Analysis of Gene

Regulatory Networks of the

FVE-HDA6-FLD Complex

in Arabidopsis.

Front. Plant Sci. 7:555.

doi: 10.3389/fpls.2016.00555
FVE/MSI4 is a homolog of the mammalian RbAp48 protein. We found that FVE regulates flowering time by repressing FLC through decreasing histone $\mathrm{H} 3 \mathrm{~K} 4$ trimethylation and H3 acetylation. Furthermore, FVE interacts with the histone deacetylase HDA6 and the histone demethylase FLD, suggesting that these proteins may form a protein complex to regulate flowering time. To further investigate the function of the FVE-FLD-HDA6 complex, we compared the gene expression profiles of fve, fld, and hda6 mutant plants by using RNA-seq analysis. Among the mis-regulated genes found in fve plants, 51.8 and $36.5 \%$ of them were also mis-regulated in fld and hda6 plants, respectively, suggesting that FVE, HDA6, and FLD may regulate the gene expression in the same developmental processes in Arabidopsis. Gene ontology analysis revealed that among 383 genes co-regulated by FVE, HDA6, and FLD, 15.6\% of them are involved in transcription, $8.2 \%$ in RNA metabolic process, $7.7 \%$ in response to abiotic stress, and $6.3 \%$ in hormone stimulus. Taken together, these results indicate that HDA6, FVE, and FLD co-regulate the gene expression in multiple development processes and pathways.

Keywords: MSIL, FVE, histone deacetylase, HDA6, flowering, Arabidopsis

\section{INTRODUCTION}

MSI1-like WD40 repeat (MSIL) proteins are subunits of many protein complexes controlling chromatin dynamics (Hennig et al., 2005). MSI1 was first found in a screen for multicopy suppressors of the ira1 mutation in yeast and was therefore termed MSI1. Most MSIL proteins contain seven WD40 domains (Smith et al., 1999; Van Nocker and Ludwig, 2003). The number and sequence of intervening amino acids between individual WD40 repeats are different in MSIL proteins compared with other WD40 repeat proteins (Vermaak et al., 1999). In Arabidopsis, three clades are represented by MSI1, MSI2, and MSI3, as well as MSI4/FVE and MSI5 (Hennig et al., 2005). The function of MSIL proteins in plants has also been characterized. Loss of MSI1 function in Arabidopsis causes seed abortion (Köhler et al., 2003; Ausín et al., 2004; Guitton et al., 2004; Kim et al., 2004). FVE/MSI4 was identified by screening for late flowering mutants in Arabidopsis (Koornneef et al., 1991; Ausín et al., 2004). It was found that FVE/MSI4 is required for transcriptional repression of FLOWERING LOCUS C (FLC) encoding a repressor of the transition from vegetative to reproductive development in Arabidopsis.

In plants, the transition from a vegetative to a reproductive phase is critical to reproductive success and is genetically controlled by a network of flowering genes (He, 2009). In Arabidopsis, 
multiple genetic pathways act in response to developmental cues and environmental signals to control the floral transition, including vernalization, autonomous, photoperiod, and gibberellin-dependent pathways (Mouradov et al., 2002; Boss et al., 2004). FLC encodes an MADS-box transcription factor and plays a central role in flowering-time regulation in Arabidopsis (Michaels and Amasino, 1999; Sheldon et al., 1999). In winter annual plants, FRIGIDA (FRI) and a FRI relative FRI LIKE 1 (FRL1) act to up-regulate the expression of FLC, whereas a non-functional FRI allele (such as Col ecotype) contributes to the early flowering phenotype (Johanson et al., 2000; Michaels et al., 2003).

The vernalization and autonomous pathways converge on and repress the expression of FLC. Prolonged cold exposure (vernalization) leads to a series of repressive histone modifications in FLC chromatin, including histone deacetylation, H3K4 demethylation, as well as H3K9 and H3K27 di- and trimethylation (Bastow et al., 2004; Sung and Amasino, 2004; Sung et al., 2006; Finnegan and Dennis, 2007). Genetic screening identified a number of autonomous pathway genes including FVE, FLD, LD, FLK, FY, FCA, and FPA (Koornneef et al., 1998; Simpson, 2004). Mutations in these loci result in late flowering in both long day and short day photoperiods (Koornneef et al., 1998; Simpson, 2004). RNA processing plays a crucial role in the autonomous pathway. The function of FCA, FPA, and FY involves a set of long non-coding antisense transcripts termed COOLAIR at the FLC locus (Hepworth and Dean, 2015). Both FCA and FPA are RNA-recognition motif (RRM)-type RNAbinding proteins and they function partially redundantly to control alternative splicing and $3^{\prime}$-end processing of mRNAs (Hornyik et al., 2010). FY is a cleavage and poly(A) specificity factor component. FCA and FPA act with FY and the cleavage stimulation factors CstF64 and CstF77 to promote the choice of the proximal poly(A) site (Liu et al., 2010). This process is also regulated by the activity of the core spliceosome component PRP8 and CYCLIN DEPENDENT KINASE GROUP C2 (CDKC2; Marquardt et al., 2014; Wang et al., 2014). In addition, other proteins such as GRP7 and PRP39 involved in various aspects of RNA metabolism have also been associated with the autonomous pathway (Wang et al., 2007; Streitner et al., 2008).

More recent studies indicated that histone modifications are also involved in the autonomous pathway of flowering. FLD encoding a Lysine Specific Demethylase1 (LSD1) type histone demethylase is involved in the histone $\mathrm{H} 3$ lysine 4 demethylation (He et al., 2003; Liu et al., 2007). The histone deacetylase HDA6 regulates flowering time by directly interacting with FLD (Yu et al., 2011). Increased levels of histone H3 acetylation and $\mathrm{H} 3 \mathrm{~K} 4$ trimethylation at FLC were found in both hda6 and fld mutant plants, suggesting that both HDA6 and FLD are involved in FLC repression by histone deacetylation and demethylation. Analysis of fld mutants also suggested a positive feedback mechanism coupling histone methylation with COOLAIR splicing and polyadenylation (Liu et al., 2010; Marquardt et al., 2014). Alternative processing of COOLAIR leads to histone methylation changes of FLC, which provides a positive feedback loop reinforcing splicing and chromatin modification outcomes. Furthermore, HDA6 was also shown to associate with FVE/MSI4 in repression of FLC expression (Gu et al., 2011). Collectively, these data suggested that HDA6 may form a HDAC complex with FVE and FLD to regulate gene expression in control of flowering time.

In this study, we further investigated the function of FVE and its interaction with HDA6 and FLD. We showed that FVE regulates flowering time by repressing FLC through decreasing $\mathrm{H} 3 \mathrm{~K} 4$ trimethylation and $\mathrm{H} 3$ acetylation. Furthermore, transcriptome analysis indicated that FVE, HDA6, and FLD co-regulate the gene expression involved in cell wall-loosening, transport, transcription, and hormone signaling in Arabidopsis.

\section{MATERIALS AND METHODS}

\section{Plant Materials}

Arabidopsis plants were grown under long day (16 h light, $8 \mathrm{~h}$ dark) or short day ( $8 \mathrm{~h}$ light, $16 \mathrm{~h}$ dark) conditions. hda6-6 (axe1-5) is a hda6 mutant carrying a point mutation on HDA6 splicing site (Murfett et al., 2001), whereas fve-4 has a point mutation resulting an early stop in translation of FVE (Ausín et al., 2004; Kim et al., 2004). fld-6 is a T-DNA insertion mutant line (SAIL_642_C05) carrying a T-DNA insertion in the second exon of FLD (Yu et al., 2011).

\section{RNA Extraction and Quantitative RT-PCR Analysis}

Total RNA was isolated with the TRIZOL Reagent (Invitrogen) according to the manufacture's protocol. To synthesize cDNA, 2 microgram of total RNA was used to synthesize cDNA by MMLV Reverse Transcriptase (Promega). Real-time PCR was performed by using iQ SYBR Green Supermix solution (Bio$\mathrm{Rad})$. The gene specific primers used for real-time RT-PCR are listed in Supplementary Table S12. Each sample was quantified at least in triplicates and normalized using Ubiquitin10 (UBQ) as an internal control.

\section{Chromatin Immunoprecipitation Assays}

Chromatin immunoprecipitation (ChIP) assays were performed as described (Yu et al., 2011). The chromatin was sheared to an average length of $500 \mathrm{bp}$ by sonication for immunoprecipitation. The following antibodies were used: anti-acetylated histone H3K9K14 (Millipore; Catalog no. 06-599), anti-tri-methylated histone H3K4 (Millipore; Catalog no. 04-745), and anti-trimethylated histone H3K27 (Millipore; Catalog no. 17-622). The DNA cross-linked to immunoprecipitated proteins was reversed and recovered by Phenol: Chloroform: Isoamyl Alcohol (25:24:1) purification. Then, the DNA was analyzed by real-time PCR using specific primers (Supplementary Table S12).

\section{Bimolecular Fluorescence Complementation (BiFC) Assays}

To generate the constructs for BiFC assays, full-length cDNA fragments of HDA6, FVE, and FLD were PCR-amplified and cloned into the pCR8/GW/TOPO (Invitrogen) vectors, and 
A

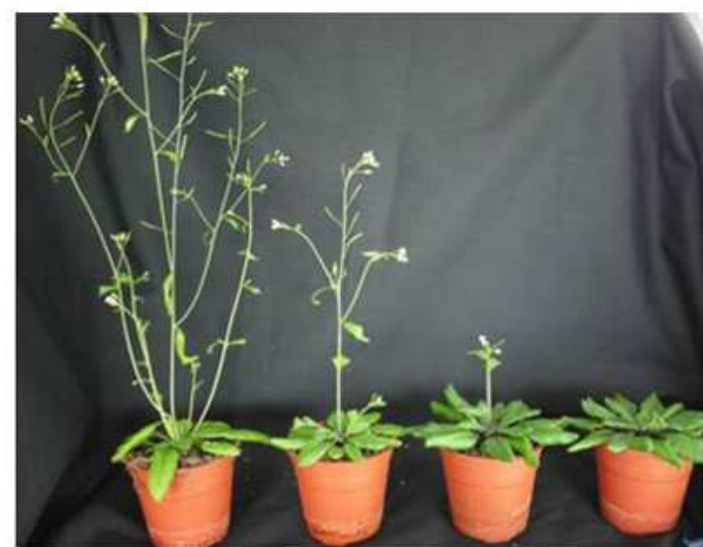

Col hda6-6 fve-4 hda6-6five-4

C

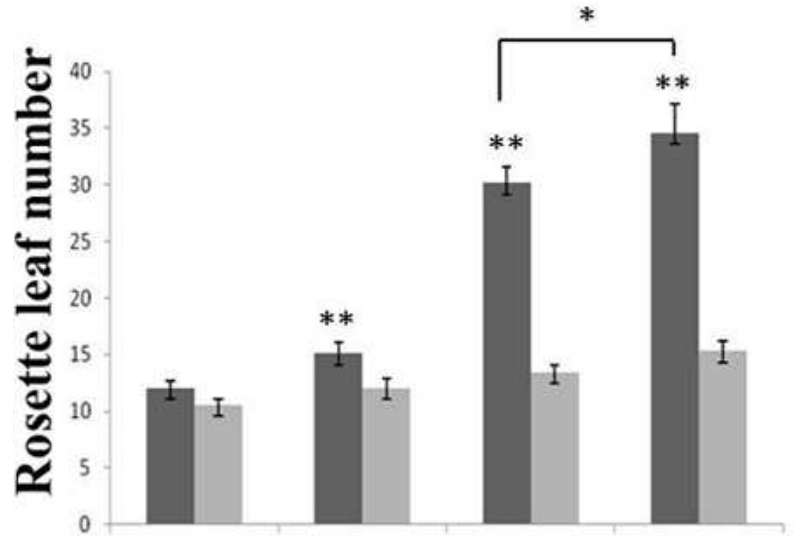

Col hda6-6 fve-4 hda6-6fve-4

E

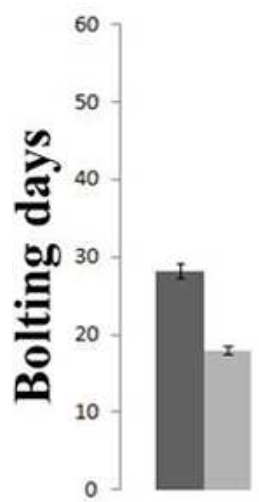

Col

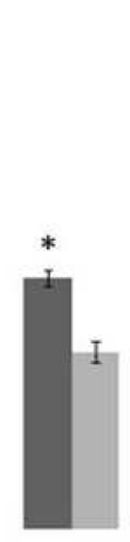

hda6-6

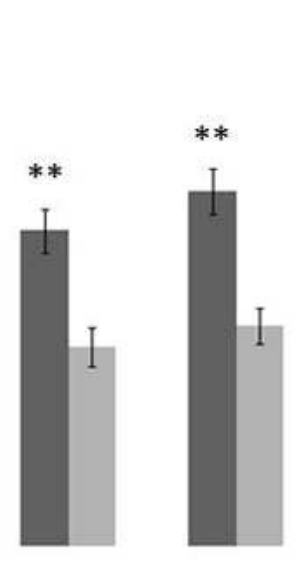

fve-4 hda6-6fve-4
B

SD

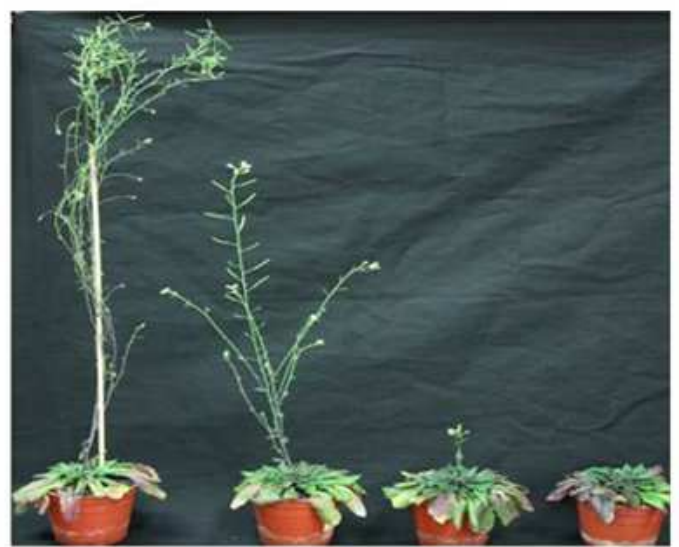

Col

hda6-6 fve-4 hab6-6five-4 D

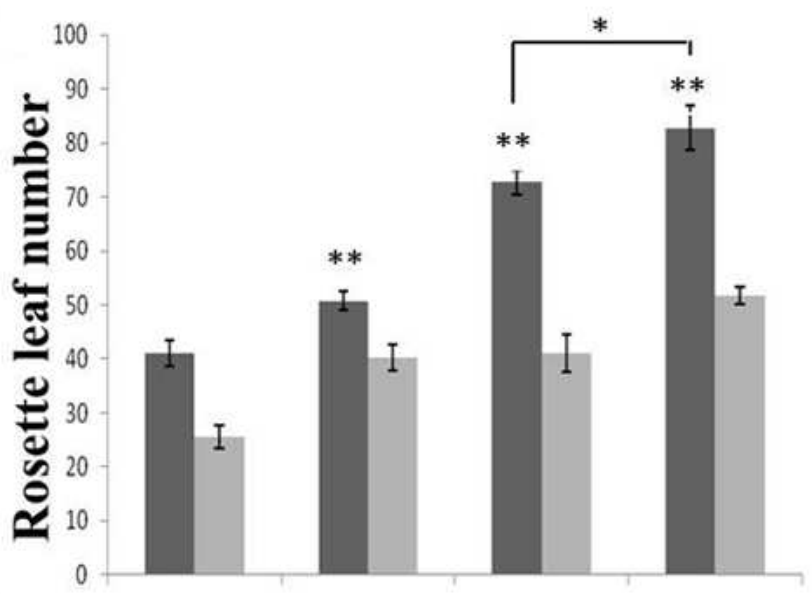

Col hda6-6 fve-4 hda6-6fve-4 F

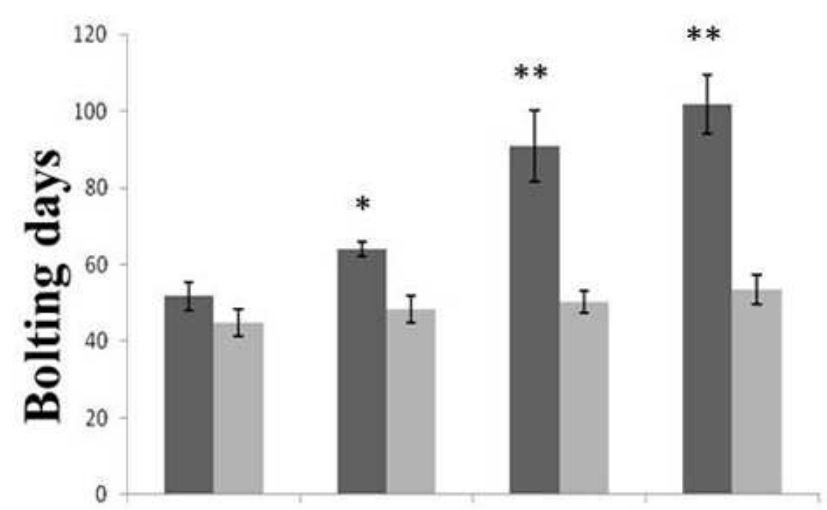

Col hda6-6 fve-4 hda6-6fve-4

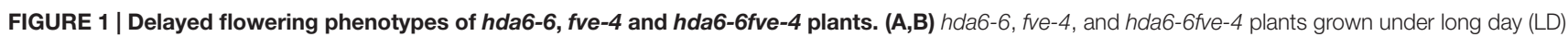
and short day (SD) conditions compared with Col wild type. (C-F) Rosette leaf numbers and bolting days of Col, hda6-6, fve-4, and hda6-6fve-4 plants grown under LD and SD without vernalization (black columns) or with 45 days vernalization (gray columns). At least 20 plants were scored for each line. Error bars indicate SD. ${ }^{*} P<0.05,{ }^{* *} P<0.01$ (t-test). 
then recombined into the YN (pEarleyGate201-YN) and YC (pEarleyGate202-YC) Vectors (Lu et al., 2010). Constructed vectors were transiently transformed into tobacco (Nicotiana benthamiana) leaves. Transfected leaves were then examined using a TCS SP5 (Leica) Confocal Spectral Microscope Imaging System.

\section{Genome-Wide mRNA Sequencing}

Total RNA was prepared using a standard TRIZOL Reagent extraction method from 0.2 to $0.3 \mathrm{~g}$ of 2 -week-old Arabidopsis plants. Poly-A containing mRNA molecules were purified using poly-T oligo-attached magnetic beads. Then, cDNA was synthesized by using random Hexamer priming. The secondstrand was generated to create double-stranded cDNA. cDNA templates were purified by using the Qiagen kit followed by end repair, poly A tailing and adaptor connection. Libraries were sequenced using the Illumina HiSeq ${ }^{\mathrm{TM}}$ 2500. Illumina's CASAVA pipeline (Version 1.8) was used to produces FASTQ files. More than 20 million clean reads were obtained in each sample. All clean reads were mapped to the TAIR10 genome ${ }^{1}$. RPKM (reads per kilobase of exon model per million mapped reads; Mortazavi et al., 2008) values were computed based on these mapped reads using RackJ ${ }^{2}$, and student $T$-tests were carried out based on RPKM values. Genes were consider as significantly differentially expressed with a $p$-value $<0.05$ and relative change threshold of twofold. GO terms and functionally clusters were analyzed with the DAVID Web tools (Huang et al., 2009). Both heatmap and scatter plot analysis were done in $\mathrm{R}$ project (Severin et al., 2010). The functional clusters enrichment analysis was calculated by comparing the whole Arabidopsis genome, and the highest classification was selected for clustering.

For Col and hda6-6, three biological repeats were performed and the data are consistent for each genotype (Supplementary Figure S5). For fld-6 and fve-4, one library was analyzed for each genotype and qRT-PCR was performed to validate RNA-seq data (Supplementary Figure S4). The RNA-seq data were deposited in GeneBank (Accession number: GSE78946).

\section{RESULTS}

\section{hda6-6 and fve-4 Mutants Display Delayed Flowering}

hda6-6 (axe1-5) is a hda6 mutant carrying a point mutation on HDA6 splicing site (Murfett et al., 2001; Blevins et al., 2014), whereas fve-4 has a point mutation resulting an early stop in translation of FVE (Kim et al., 2004). To investigate the genetic interaction between HDA6 and FVE, hda6-6 fve-4 double mutants were generated by crossing hda6-6 and fve-4 mutants. Both hda6-6 and fve-4 mutant plants displayed later flowering phenotypes under long-day (LD, $16 \mathrm{~h}$ light and $8 \mathrm{~h}$ dark) and short-day (SD, $8 \mathrm{~h}$ light and $16 \mathrm{~h}$ dark) conditions (Figures 1A,B), as measured by the days of bolting and the rosette leaf numbers at flowering (Figures 1C-F). Compared

${ }^{1}$ http://www.arabidopsis.org/

${ }^{2}$ http://rackj.sourceforge.net/ to hda6-6 and fve-4 plants, the flowering time of hda6-6 fve-4 plants was further delayed under both LD and SD (Figure 1). The delay in flowering time of hda6-6, fve-4, and hda6-6 fve-4 mutants was completely corrected by 45 days of vernalization at $4^{\circ} \mathrm{C}$ (Figures 1C-F), supporting that both FVE and HDA6 are involved in the autonomous pathway of flowering transition.

We compared the expression of FLC, MAF4, and MAF5 in hda6-6, fve-4, and hda6-6 fve-4 plants by qRT-PCR. As shown in Figure 2A, FLC, MAF4, and MAF5 were up-regulated in hda66, fve-4, and hda6-6fve-4 plants compared with wild type plants. In contrast, the transcript levels of two downstream flowering integrators, FT and SOC1, as well as two flowering activators, AGL8 and SPL5, were decreased in hda6-6, fve-4, and hda6-6 fve-4 plants (Figure 2B).

\section{Histone H3 Acetylation and H3K4 Trimethylation Levels of $F L C$ are Increased in hda6-6, fve-4, and hda6-6 fve-4 Plants}

To analyze whether the high expression of FLC in mutants is related to histone modifications in chromatin, ChIP assays were used to analyze the histone $\mathrm{H} 3$ acetylation level. As shown in Figures 3A,B, hyperacetylation of histone $\mathrm{H} 3$ was found in the promoter (P), first exon (E) and intron (I) regions of FLC in hda66, fve-4, and hda6-6 fve-4 plants. ChIP assays were also used to analyze the histone H3K4 methylation level of FLC. As shown in Figure 3C, hypermethylation of histone $\mathrm{H} 3 \mathrm{~K} 4$ was also found in the promoter, first exon and intron regions of FLC in the mutants.

We further analyzed the histone H3K27 methylation level of FLC in hda6-6, fve-4, and hda6-6 fve-4 plants. As shown in Figure 3D, hypomethylation of histone H3K27 was found in the promoter, first exon and intron as well as $3^{\prime}$-UTR regions of FLC. These results suggested that HDA6 and FVE regulate the expression of FLC by affecting chromatin acetylation and methylation.

\section{Genome-Wide Transcription Analysis of fve, fld, and hda6 Mutants}

Previous studies indicated that the Arabidopsis HDA6 is associated with FLD and FVE, forming HDAC complexes that control flowering time (Gu et al., 2011; Yu et al., 2011). We found that FVE can also interact with FLD by using bimolecular fluorescence complementation (BiFC) analysis (Supplementary Figure S1). These data suggested that FVE, FLD, and HDA6 may form a protein complex to regulate gene expression. To further study the function of FVE, FLD, and HDA6 in Arabidopsis, we compared the transcriptome of $f v e-4$, fld-6, and hda6-6 mutants with wild type by RNA-sequencing. Total RNA were extracted from 14-day old plants grown under LD conditions. Genes with $\geq$ twofold increased or decreased expression and $P$-value $\leq 0.05$ were considered to have significant expression differences. Differentially expressed genes identified in the mutants are listed in Supplementary Tables S3-S8. Compared with Col wild type, $1761(62.5 \%)$ genes were up-regulated and 1057 (37.5\%) genes were down-regulated in hda6-6; 2104 (52.9\%) genes were upregulated and 1871 (47.1\%) genes were down-regulated in fve-4; 


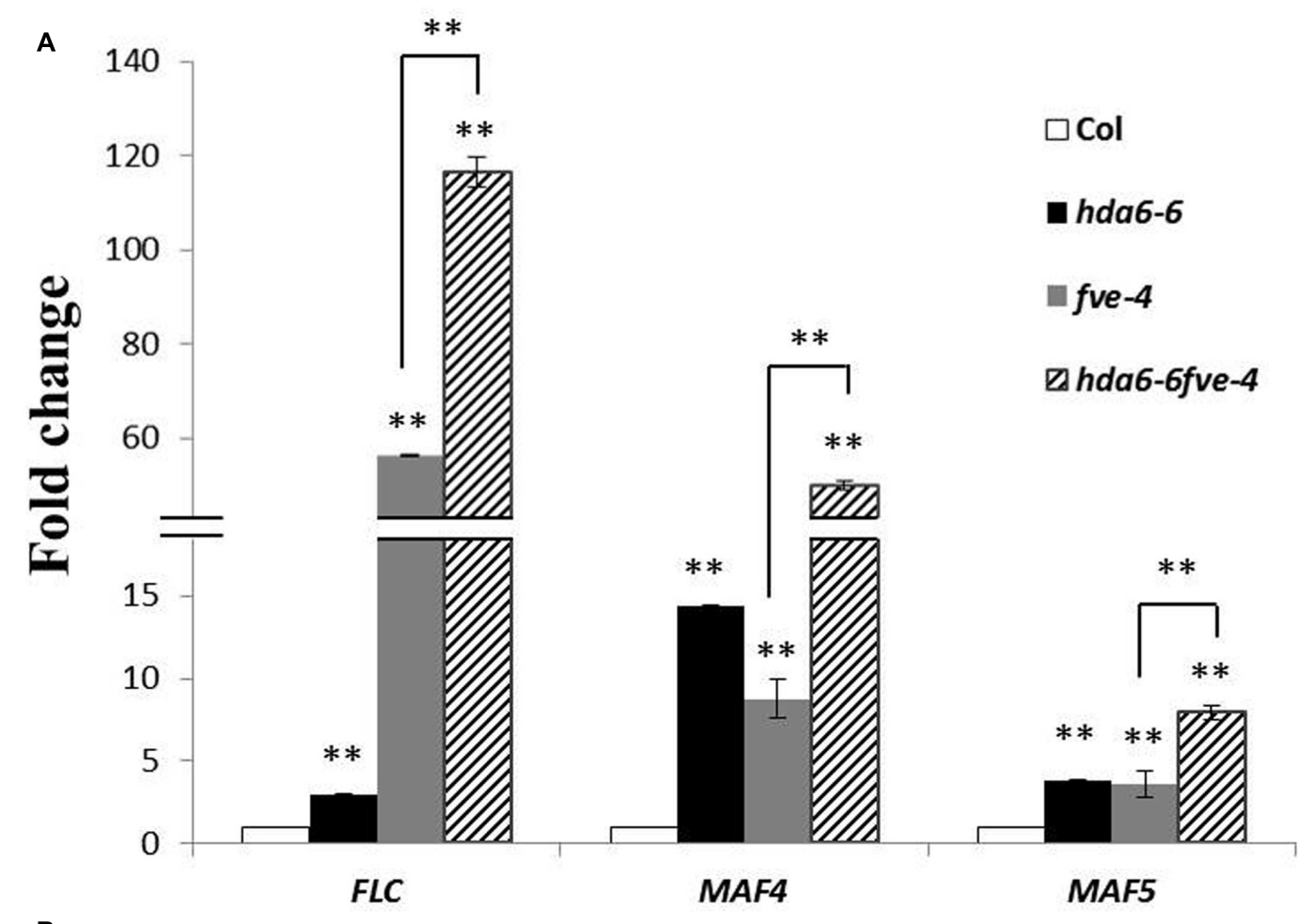

B

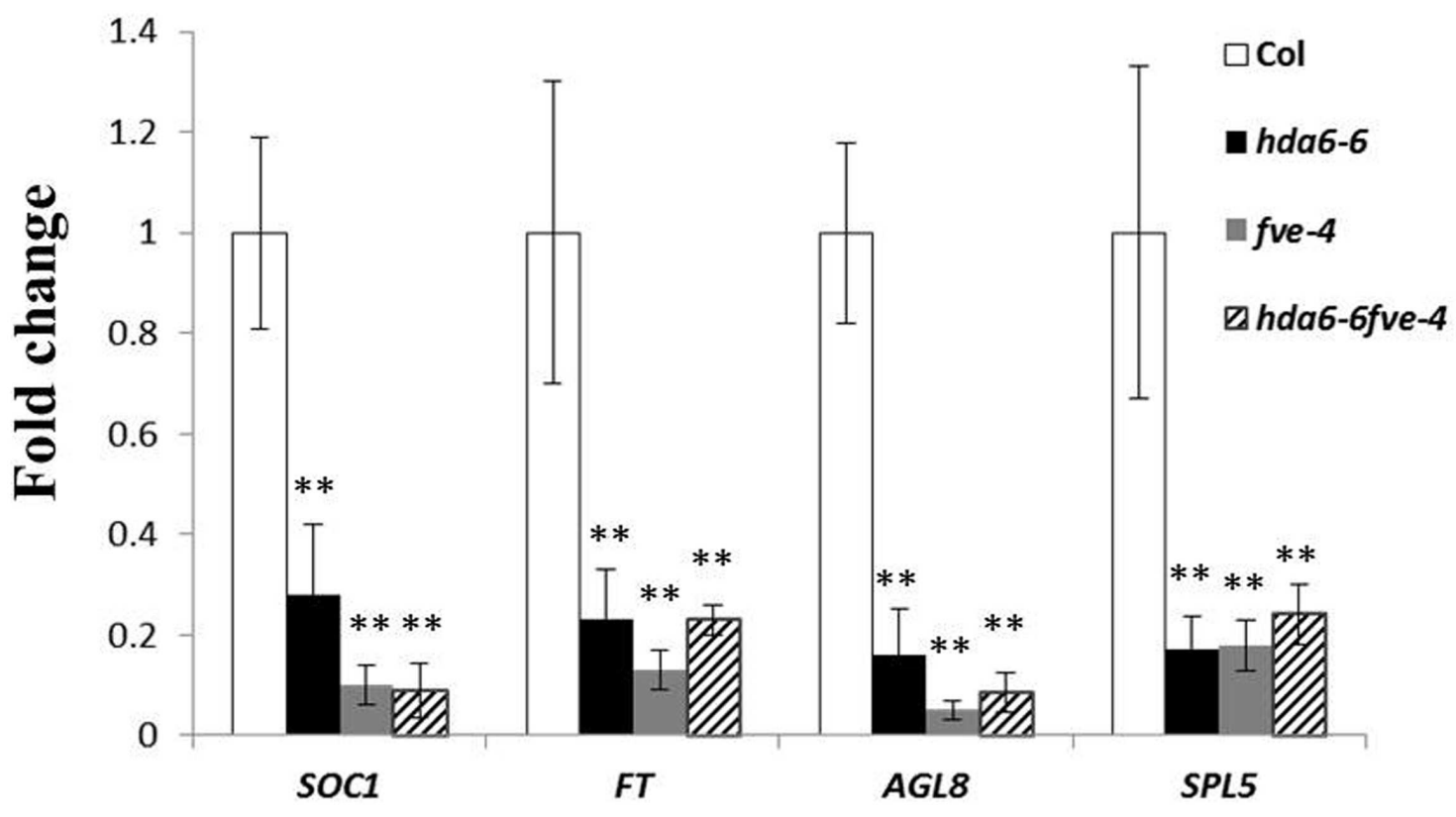

FIGURE 2 | Expression of flowering repressor and activator genes. (A) Real-time RT-PCR analysis of the expression of FLC, MAF4, and MAF5 in Col wild type, hda6-6, fve-4, and hda6-6fve-4 plants grown under LD conditions for 20 days. The values shown are means \pm SD. (B) Real-time RT-PCR analysis of the expression of SOC1, FT, AGL8, and SPL5 in Col, hda6-6, fve-4, and hda6-6fve-4 plants grown under LD conditions for 20 days. The values shown are means $\pm \mathrm{SD}$. ${ }^{* *}$ Double asterisks denote statistical significance $P<0.01$ ( $t$-test).

whereas 1226 (48.3\%) genes were up-regulated and 1313 (51.7\%) genes were down-regulated in fld-6 (Figure 4).

Among the mis-regulated genes found in $f v e-4,51.8$ and $36.5 \%$ of them were also mis-regulated in fld-6 and hda6-6, respectively
(Figure 4), suggesting that FVE, HDA6, and FLD may regulate the gene expression involved in the same developmental pathways. Among 383 genes co-regulated by FVE, HDA6, and FLD, 147 genes were up-regulated (Figure 4D), whereas 236 
A

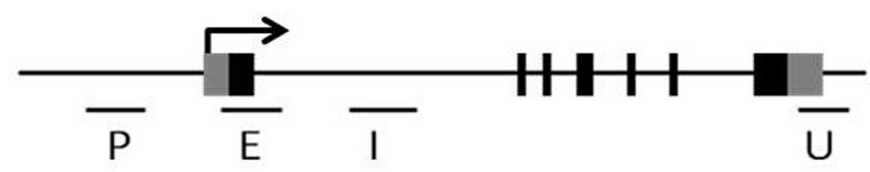

B

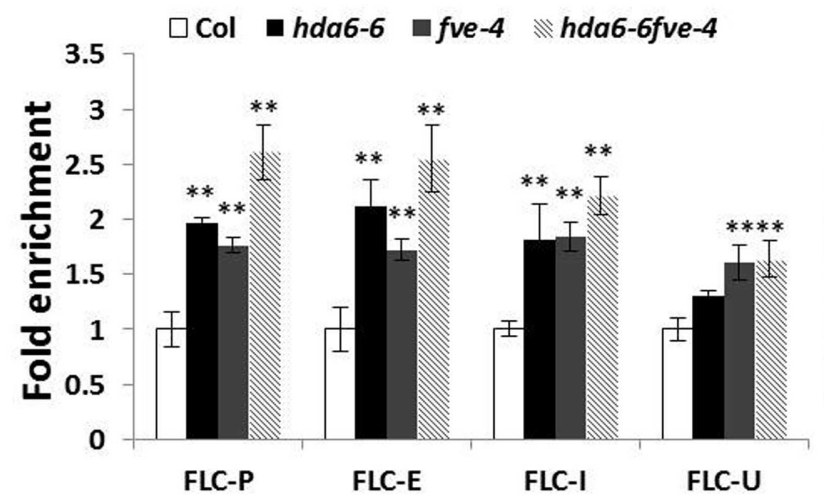

c

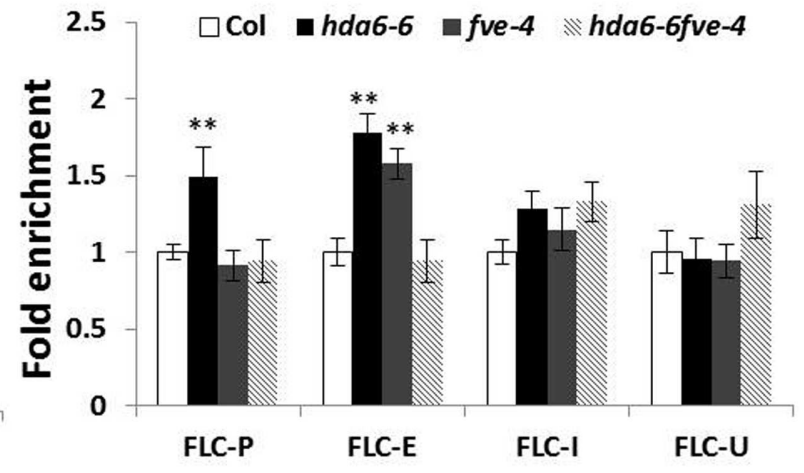

D H3K27Me3

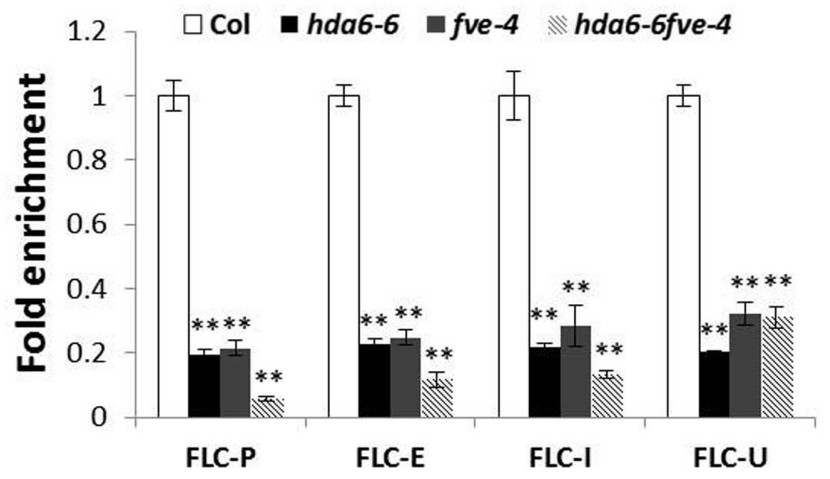

FIGURE 3 | Histone modification levels of $\boldsymbol{F L C}$ chromatin in hda6-6, fve-4, and hda6-6fve-4 mutants. (A) Schematic structure of genomic sequences of FLC and the regions examined by ChIP. (B-D) Relative levels of H3K9K14Ac (B), H3K4Me3 (C), and H3K27Me3 (D) of FLC in Col, hda6-6, fve-4, and hda6-6 fve-4 seedlings grown under LD condition for 10 days. ${ }^{* *}$ Double asterisks denote statistical significance $P<0.01$ ( $t$-test).

genes were down-regulated (Figure $\mathbf{4 H}$ ) in the mutants. Next, we performed the functionally clustered and the gene ontology (GO) analysis of these co-regulated genes by using the DAVID (The Database for Annotation, Visualization, and Integrated Discovery) resource (Huang et al., 2009). The predicted gene functions include chromatin remodeling, transcription, development, phosphorylation, metabolism, proteolysis, stress response, transport, and others (Figure 5A). In addition, GO analysis revealed that the major functions of these co-regulated genes are involved in transcription (15.6\%), RNA metabolic process $(8.2 \%)$, response to abiotic stress $(7.7 \%)$, response to hormone stimulus (6.3\%), as well as intracellular signaling cascade (6.1\%; Figure 5B).

\section{FVE, FLD, and HDA6 Co-regulate Cell Wall-Loosening, Transport, Flowering and Hormone Related Genes}

From our transcriptome analysis, we found that genes related to cell wall-loosening, transport, flowering, and hormones are 

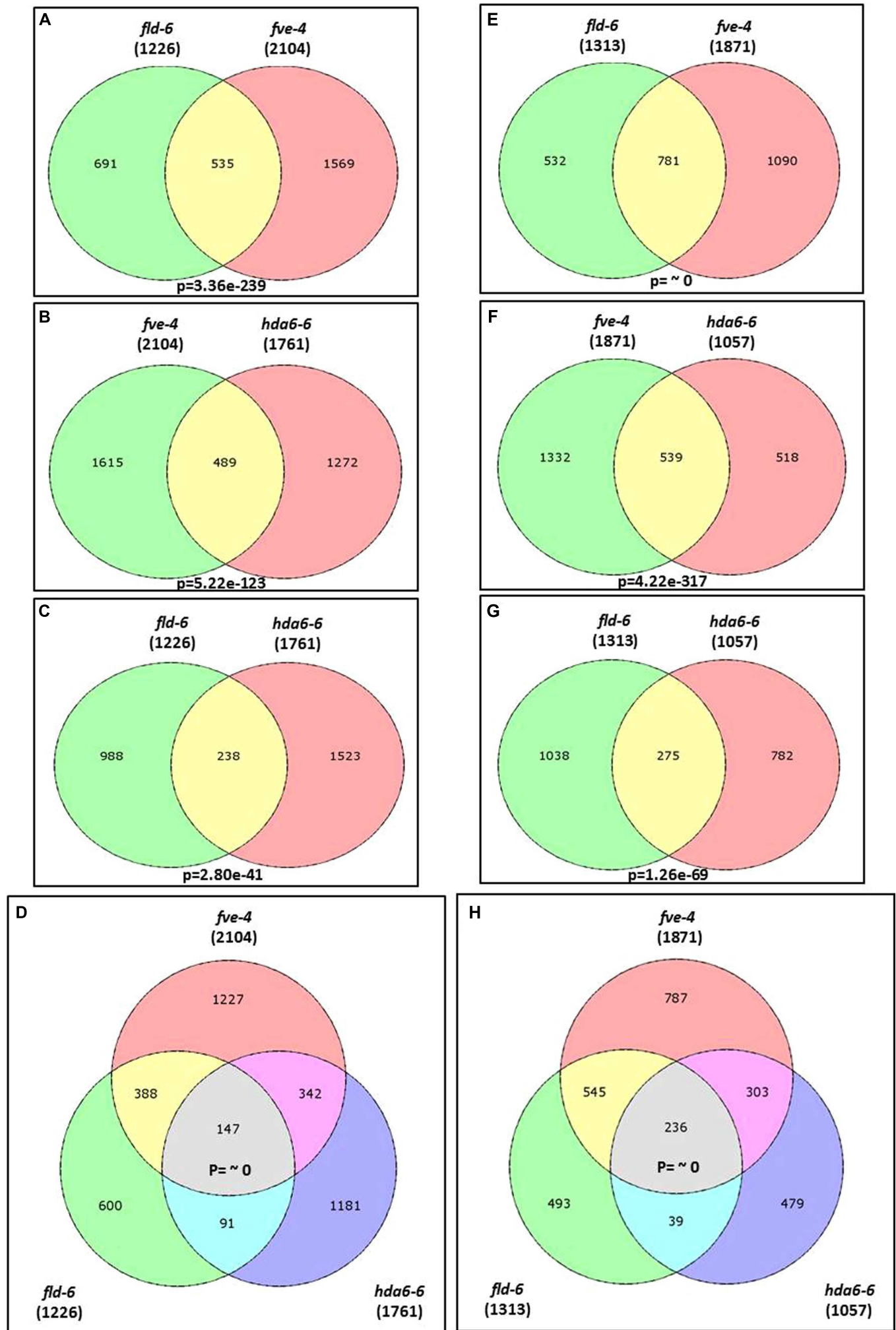

FIGURE 4 | Transcriptome profiles of fve-4, fld-6 and hda6-6 mutants. (A-D) Venn diagrams showing the number of genes up-regulated (>twofold, $p$-value < 0.05) in fve-4, fld-6, and hda6-6 mutants by using RNA-sequencing analysis. (E-H). The number of genes down-regulated (<twofold, $p$-value $<0.05)$ in fve-4, fld-6, and hda6-6 mutants. Numbers in parentheses represent the total numbers of up- or down-regulated genes in the respective mutants. The $P$-value of the Venn diagram (A-C and $\mathbf{E}-\mathbf{G})$ was calculated using the hypergeometric distribution. (D,H) Simulation-based $P$-values were calculated via R project. 

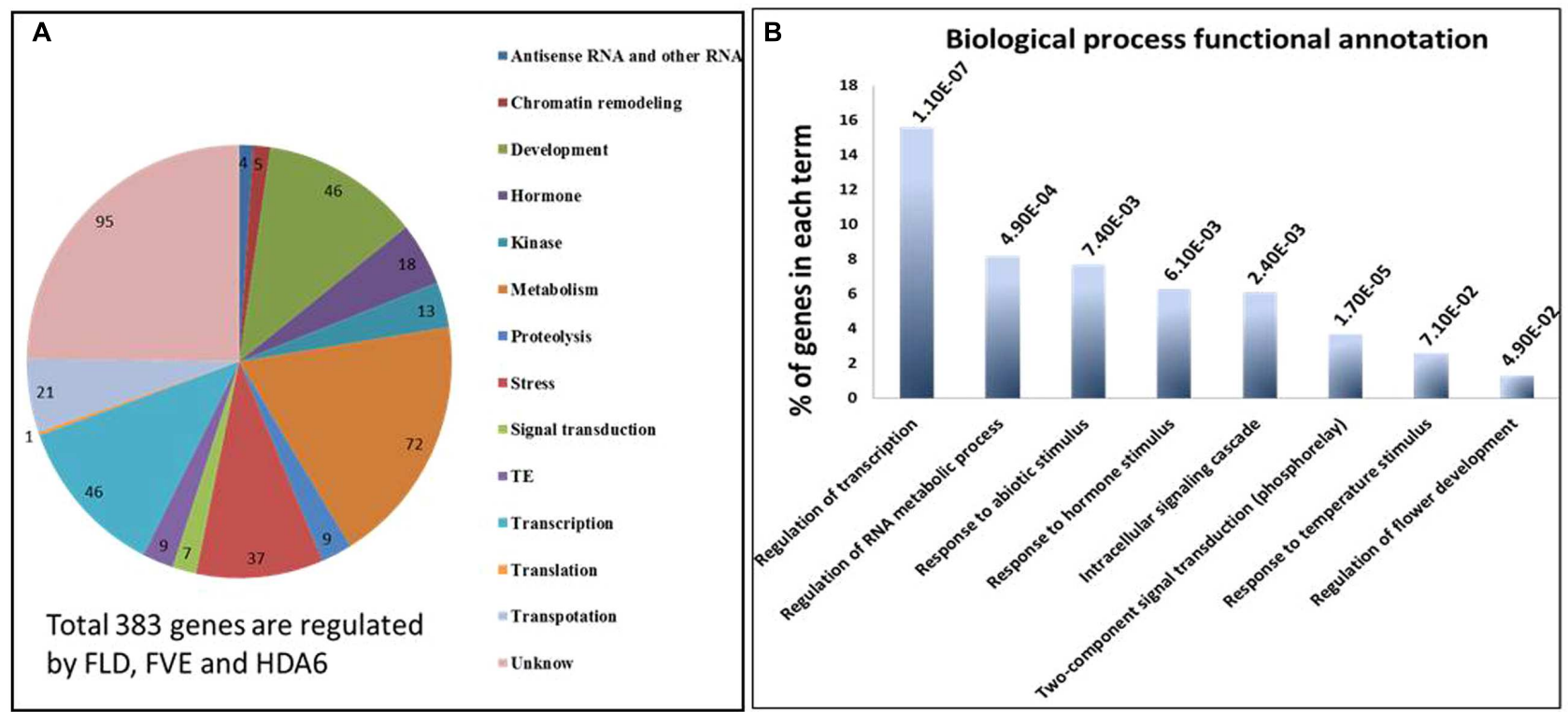

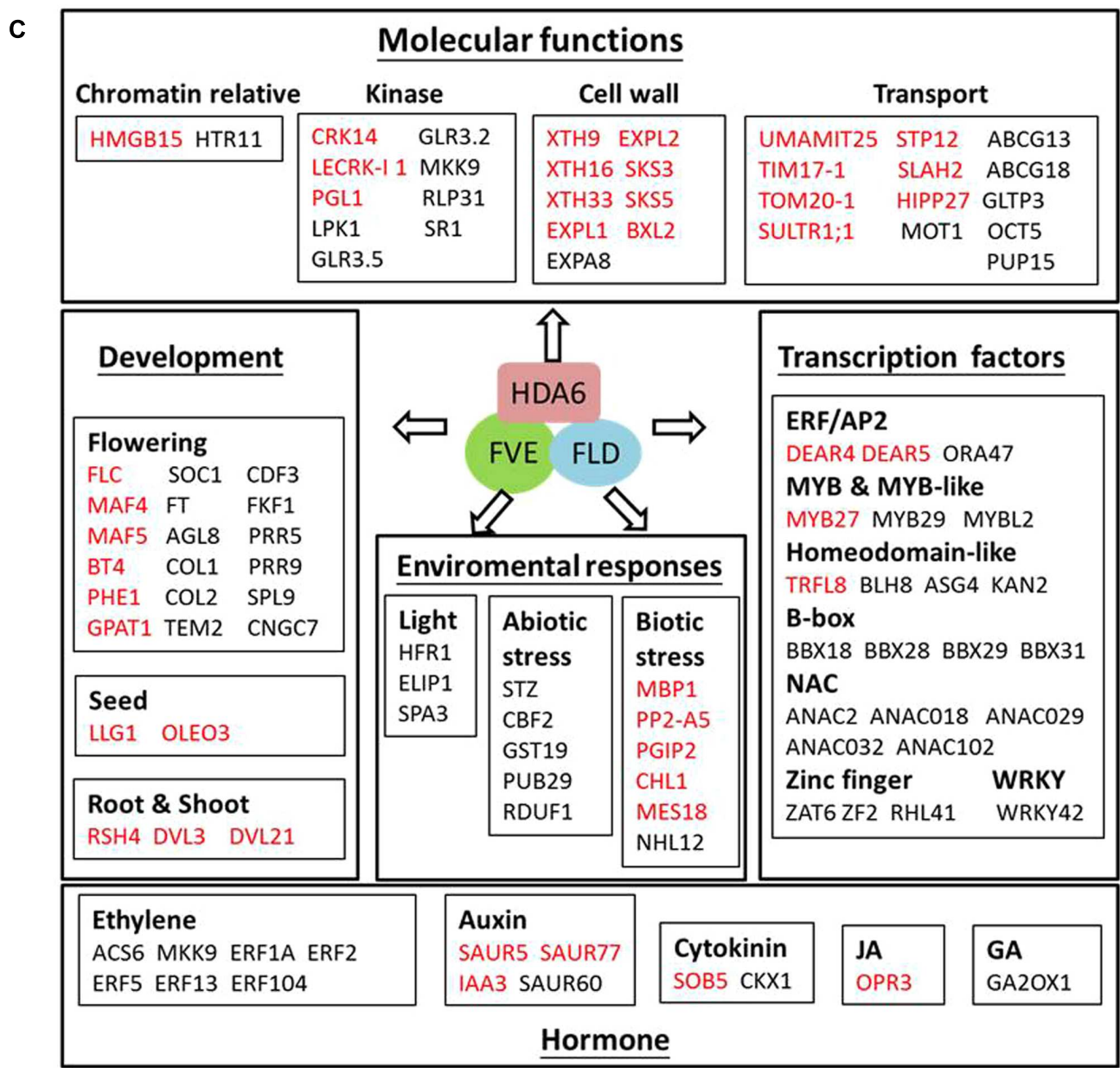

FIGURE 5 | Functional analysis of co-regulate genes in fve-4, fld-6, and hda6-6 mutants. (A) Gene Ontology classification of FVE, FLD, and HDA6 co-regulated genes. (B) DAVID functional clustering of the highly enriched GO terms in FVE-FLD-HDA6 co-regulated genes. (C) Representative FVE-FLD-HDA6 co-regulated genes with known functions in various molecular functions including development, enviromental responses, transcription regulation, and hormone responses. Genes repressed and activated by FVE-FLD-HDA6 are in red and black, respectively. 
co-regulated by FVE, FLD, and HDA6 (Figure 5C). A large number of genes that are involved in cellular processes such as cell wall and transport are co-regulated by FVE, FLD, and HDA6. SMALL AUXIN UP-RNA (SAUR) genes play a significant role in promotes cell expansion (Cosgrove, 1998; Spartz et al., 2014). In addition, xyloglucan endotransglycosylases/hydrolases (XTHs) and expansins (EXPs) are two groups of enzymes important in cell wall loosening and cell expansion (Li et al., 2003; Van Sandt et al., 2007). A number of genes encoding SAURs, XTHs, and EXPs were repressed by FVE, FLD and HDA6 (Figure 5C and Supplementary Table S1), suggesting that the FVE-FLD-HDA6 module plays a role in stabilizing the cell wall.

The transition of nutrients and metals play essential roles in physiological processes including plant growth, nutrition, signal transduction, and development (Hall and Williams, 2003). In Arabidopsis genome, approximately $5 \%$ of genes (more than 800 genes) encode membrane transport proteins (Mäser et al., 2001). Our RNA-sequencing analysis revealed that at least 21 genes related to nutrient and metal transport including UMAMIT25, TIM17-1, TOM20-1, SULTR1;1, STP12, HIPP27, ABCG13, ABCG18, GLTP3, MOT1, OCT5, and PUP15 were affected in the mutants (Supplementary Tables S1 and S2; Figure 5C).

In addition, several genes related to hormone biosynthesis and signaling were also mis-regulated in $f v e-4, f l d-6$, and hda6-6 mutants (Figure 5). The expression of ACS6 encoding 1-Aminocyclopropane-1-Carboxylic Acid (ACC) synthase in ethylene biosynthesis was down-regulated in fve-4, fld-6, and hda6-6 mutants (Supplementary Table S2; Figure 5C). Furthermore, the expression of MKK9, ERF2, and ERF5 involved in ethylene signaling was all reduced in the mutants. These data suggest that FVE, FLD, and HDA6 may co-regulate the gene expression involved in ethylene biosynthesis and signaling.

\section{FVE Regulates Gene Expression Involved in RNA Processing and Temperature Stimulus}

We further performed the scatterplot and heat map analysis of FVE, FLD, and HDA6 regulated genes (Figure 6). Although FVE, FLD, and HDA6 co-regulate a large number of genes (Figures 6A-C, black circle), they also have specialized functions (red, yellow, and green circle in Figures 6A-C). The heat map analysis showed the similar patterns among fve-4, fld6, and hda6-6 regulated genes, but several groups of genes were also independently regulated by FVE, FLD, or HDA6 (Figure 6D).

To gain further insight into the individual biological roles of FVE, FLD, and HDA6, we selected the up-regulated genes in each mutant for further analysis (Supplementary Figures S3A-F; Supplementary Tables S9-S11). In the fve4 mutant, a high enrichment in terms related to RNA processing was observed (Supplementary Figure S3A). Also, genes responding to temperature stimulus were also enriched, consisting with the proposed function of FVE in cold stress regulation (Kim et al., 2004). A high proportion of genes involved in ribonucleoprotein complex biogenesis, non-coding RNA (ncRNA) metabolic process, ribosome biogenesis, as well as a cell wall organization were identified, suggesting the potential role of FVE in these processes.

The GO analysis also highlighted the potential role of HDA6 in oxidation-reduction, defense response, phosphorylation, intracellular signaling cascade, cell death, as well as cell wall organization (Supplementary Figure S3C). High proportion genes are found in oxidation-reduction, defense response, and cell death, consistent with previous studies showing that HDA6 is required for abiotic stress and plant defense (Chen et al., 2010; Zhu et al., 2011). Interesting, 57 genes related to phosphorylation were exclusive to the hda6 mutant (hda6-6; Supplementary Figure S3C; Supplementary Table S11). Also, a large number of transposons were specifically up-regulated in the hda6-6 mutant (Supplementary Figures S2 and S3F; Supplementary Table S11), supporting the role of HDA6 in controlling the stability of transposons.

\section{DISCUSSION}

MSIL proteins were found in all eukaryotes but seem to be absent in prokaryotes (Hennig et al., 2005). In mammalian and yeast cells, MSIL proteins are subunits of many protein complexes controlling chromatin assembly, DNA damage repair, and stresssensing signaling pathways (Hennig et al., 2005; Yang et al., 2013). Most of the MSIL proteins contain seven WD40 repeats and are believed to form a $\beta$-propeller fold structure which is important for protein-protein interactions (Smith et al., 1999).

In plants, Arabidopsis thaliana contains five MSIL proteins (MSI1 to MSI5), while rice (Oryza sativa) and Zea mays have three MSIL proteins. The Arabidopsis MSIL proteins can be classify into three main clades, including MSI1, MSI2/MSI3, and MSI4/MSI5 (Hennig et al., 2005). Arabidopsis MSI1 is a component of the MEA/FIE polycomb group complex, and loss of function of MSI1 causes seed abortion, indicating that MSI1 is required for seed development (Köhler et al., 2003). FVE/MSI4 has been shown to repress expression of the central floral repressor $F L C$ and several cold-responsive genes, including COR15a and COR47 in Arabidopsis (Ausín et al., 2004; Kim et al., 2004). More recently, MSI5 was found to acts in partial redundancy with MSI4/FVE to silence FLC by associating with HDA6 (Gu et al., 2011; Yu et al., 2011).

The transition from vegetative to reproductive development in Arabidopsis is controlled by several independent pathways. FLC is a major repressor in flowering and is epigenetically regulated in response to both endogenous and environmental cues (Michaels and Amasino, 2001; He, 2009). The autonomous pathway genes including FLD, HDA6, and FVE repress the FLC expression through histone modifications. FLD is a lysinespecific demethylase 1-type histone demethylase involved in the removes methyl groups from mono- and dimethylated histone H3K4 (Jiang et al., 2007; Liu et al., 2007). HDA6 is a histone deacetylase catalyzing the removal of acetyl groups from lysine residues of histone. We found that FVE can interact with both FLD and HDA6, indicating that these proteins may be part of 

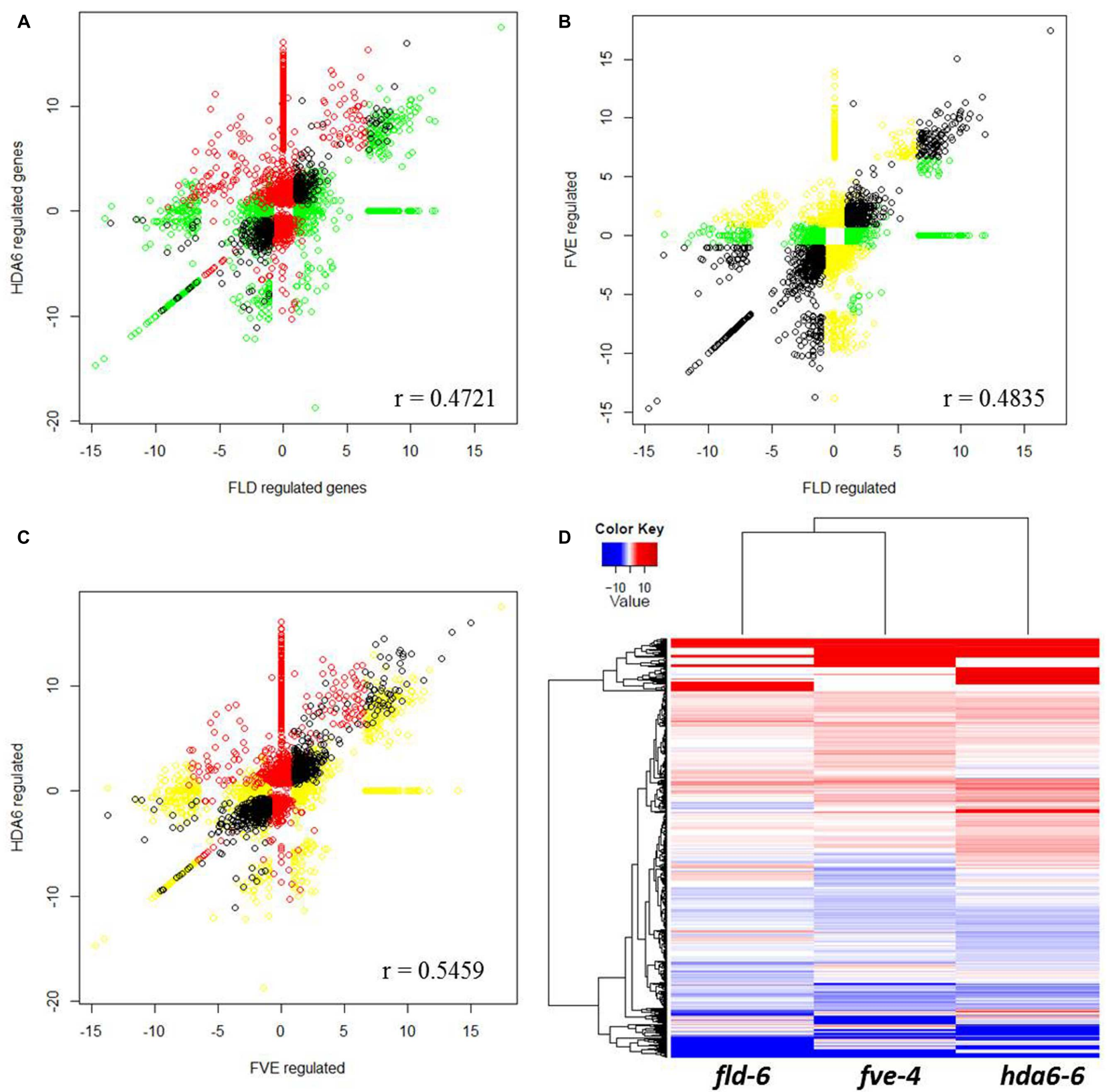

FIGURE 6 | Scatterplot analysis of FVE, FLD, and HDA6 regulated genes. (A-C) Correlation by scatterplot of log2 fold change values between HDA6 and FLD regulated genes (A), FVE and FLD regulated genes (B) and HDA6 and FVE regulated genes (C). Correlation coefficient was calculated and shown in figure. (D) Transcriptional profiles comparisons represented as a heatmap to highlight up-regulated (red) and down-regulated (blue) genes in fve-4, fld-6, and hda6-6 mutants.

the same protein complex. Similar to hda6 and fld mutants (Yu et al., 2011), increased levels of histone $\mathrm{H} 3$ acetylation and H3K4 trimethylation at FLC were also found in fve plants. These data support a scenario in which FLC repression associated with histone deacetylation and $\mathrm{H} 3 \mathrm{~K} 4$ demethylation in the autonomous pathway is mediated by the interaction of FVE with HDA6 and FLD.

FLOWERING LOCUS $C$ is epistatic to FLD regarding flowering time, since the flc fld double mutant flowers as late as a flc single mutant (He et al., 2003). By contrast, the hda66 mutant delays flowering even in an $f l c-3$ mutant background (Yu et al., 2011), suggesting that HDA6 may control flowering independent of FLC regulation. The flowering time phenotypes in fld and fve mutants are much stronger compared to had6 mutants. Furthermore, hda6 fld and hda6 fve double mutants are later flowering compared to fld and fve single mutants, supporting non-redundant roles of HDA6 and FVE/FLD. A likely explanation may be functional redundancy between members of 
the HDAC protein family. Indeed, another HDAC, HDA5, was also found to be involved in flowering by interacting with FVE and FLD (Luo et al., 2015).

Histone H3K27 methylation is regulated by the Polycomb Repressor Complex 1 (PRC1) and PRC2 (Dellino et al., 2004; Francis et al., 2004; King et al., 2005). PRC2 acts as a histone methyl-transferase that catalyzes tri-methylation of histone $\mathrm{H} 3 \mathrm{~K} 27$, whereas PRC1 inhibits transcription and blocks remodeling of the target nucleosomes by binding the H3K27me3 marks. Drosophila PRC2 has been shown to be associated with histone deacetylases, suggesting that histone deacetylation is linked to the PRC2-mediated gene repression suppression (Tie et al., 2001). Recent studies showed that MSI4 represses FLC expression through its association with a PRC2 complex in Arabidopsis (Frolov and Dyson, 2004; Pazhouhandeh et al., 2011). In this study, hypomethylation of histone H3K27 was found in FLC chromatin of both fve and hda6 mutants. Taken together, these results support that the FLD-FVE-HDA6 complex may act with the PRC2 complex to silence FLC in flowering regulation.

Among the mis-regulated genes found in fve-4, 51.8 and $36.5 \%$ were also mis-regulated in fld-6 and hda6-6, respectively. The overlap among the mis-regulated genes in these mutants suggested that FVE, FLD, and HDA6 may functional together to control multiple plant developmental pathways. The SAUR1924 subfamily of SAUR proteins play a significant role in promoting cell expansion (Cosgrove, 1998; Spartz et al., 2014). In addition, EXPs and XTHs were proposed to act as cell wallloosening agents (Fry et al., 1992; Nishitani and Tominaga, 1992; Cosgrove, 2000). We found that many members of SAUR, EXP, and XTH genes were repressed by FVE, FLD, and HDA6 (Supplementary Tables S1, S5, and S7; Figure 5C), suggesting that the FLD-FVE-HDA6 complex is involved in the regulation of cell expansion.

ABCG transporters are required for suberin and pollen wall extracellular barriers in Arabidopsis (Yadav et al., 2014). Five Arabidopsis ABCG transporters including ABCG2, ABCG6, and ABCG20 are required for synthesis of an effective suberin barrier in roots and seed coats, whereas ABCG1 and ABCG16 are

\section{REFERENCES}

Ausín, I., Alonso-Blanco, C., Jarillo, J. A., Ruiz-García, L., and Martínez-Zapater, J. M. (2004). Regulation of flowering time by FVE, a retinoblastoma-associated protein. Nat. Genet. 36, 162-166. doi: 10.1038/ng1295

Bastow, R., Mylne, J. S., Lister, C., Lippman, Z., Martienssen, R. A., and Dean, C. (2004). Vernalization requires epigenetic silencing of FLC by histone methylation. Nature 427, 164-167. doi: 10.1038/nature02269

Blevins, T., Pontvianne, F., Cocklin, R., Podicheti, R., Chandrasekhara, C., Yerneni, S., et al. (2014). A two-step process for epigenetic inheritance in Arabidopsis. Mol. Cell 54, 30-42. doi: 10.1016/j.molcel.2014.02.019

Boss, P. K., Bastow, R. M., Mylne, J. S., and Dean, C. (2004). Multiple pathways in the decision to flower: enabling, promoting, and resetting. Plant Cell 16, S18-S31. doi: 10.1105/tpc.015958

Chen, L.-T., Luo, M., Wang, Y.-Y., and Wu, K. (2010). Involvement of Arabidopsis histone deacetylase HDA6 in ABA and salt stress response. J. Exp. Bot. 61, 3345-3353. doi: 10.1093/jxb/erq154

Cosgrove, D. J. (1998). Cell wall loosening by expansins. Plant Physiol. 118, 333-339. doi: 10.1104/pp.118.2.333 required for the development of pollen wall (Yadav et al., 2014). We found that the expression of $A B C G 13$ and $A B C G 18$ was reduced in fve-4, fld-6, and hda6-6 mutants (Supplementary Table S2). In addition to $A B C G 13$ and $A B C G 18$, our RNA-sequencing analysis revealed that at least 21 genes related to nutrient and metal transport were also affected in the mutants (Supplementary Tables S1 and S2, Figure 5C), supporting that the FLD-FVEHDA6 complex is required for controlling transport in plants. Further research is required to reveal the molecular mechanism of the involvement of the FLD-FVE-HDA6 complex in the regulation cell expansion and transport.

\section{AUTHOR CONTRIBUTIONS}

$\mathrm{C}-\mathrm{WY}$ and $\mathrm{KW}$ conceived this project and designed all research. $\mathrm{C}-\mathrm{WY}$ and K-YC performed the research. C-WY and KW analyzed data and wrote the article.

\section{FUNDING}

This work was supported by the Ministry of Science and Technology of Taiwan (101-2311-B-002-012-MY3 and 104-2321B-002-004-) and National Taiwan University (104R892005).

\section{ACKNOWLEDGMENT}

We thank Technology Commons, College of Life Science, National Taiwan University for the convenient use of the BioRad real-time PCR system and the confocal spectral microscope imaging system.

\section{SUPPLEMENTARY MATERIAL}

The Supplementary Material for this article can be found online at: http://journal.frontiersin.org/article/10.3389/fpls.2016.00555

Cosgrove, D. J. (2000). Loosening of plant cell walls by expansins. Nature 407, 321-326. doi: 10.1038/35030000

Dellino, G. I., Schwartz, Y. B., Farkas, G., McCabe, D., Elgin, S. C., and Pirrotta, V. (2004). Polycomb silencing blocks transcription initiation. Mol. Cell 13, 887893. doi: 10.1016/S1097-2765(04)00128-5

Finnegan, E. J., and Dennis, E. S. (2007). Vernalization-induced trimethylation of histone $\mathrm{H} 3$ lysine 27 at FLC is not maintained in mitotically quiescent cells. Curr. Biol. 17, 1978-1983. doi: 10.1016/j.cub.2007.10.026

Francis, N. J., Kingston, R. E., and Woodcock, C. L. (2004). Chromatin compaction by a polycomb group protein complex. Science 306, 1574-1577. doi: 10.1126/science. 1100576

Frolov, M. V., and Dyson, N. J. (2004). Molecular mechanisms of E2F-dependent activation and pRB-mediated repression. J. Cell Sci. 117, 2173-2181. doi: $10.1242 /$ jcs. 01227

Fry, S., Smith, R. C., Renwick, K. F., Martin, D. J., Hodge, S., and Matthews, K. J. (1992). Xyloglucan endotransglycosylase, a new wall-loosening enzyme activity from plants. Biochem. J. 282, 821-828. doi: 10.1042/bj2820821

Gu, X., Jiang, D., Yang, W., Jacob, Y., Michaels, S. D., and He, Y. (2011). Arabidopsis homologs of retinoblastoma-associated protein $46 / 48$ associate with a histone 
deacetylase to act redundantly in chromatin silencing. PLoS Genet. 7:e1002366. doi: 10.1371/journal.pgen.1002366

Guitton, A.-E., Page, D. R., Chambrier, P., Lionnet, C., Faure, J.-E., Grossniklaus, U., et al. (2004). Identification of new members of Fertilisation Independent Seed Polycomb Group pathway involved in the control of seed development in Arabidopsis thaliana. Development 131, 2971-2981. doi: $10.1242 /$ dev. 01168

Hall, J., and Williams, L. E. (2003). Transition metal transporters in plants. J. Exp. Bot. 54, 2601-2613. doi: 10.1093/jxb/erg303

He, Y. (2009). Control of the transition to flowering by chromatin modifications. Mol. Plant 2, 554-564. doi: $10.1093 / \mathrm{mp} / \mathrm{ssp} 005$

He, Y., Michaels, S. D., and Amasino, R. M. (2003). Regulation of flowering time by histone acetylation in Arabidopsis. Science 302, 1751-1754. doi: 10.1126/science. 1091109

Hennig, L., Bouveret, R., and Gruissem, W. (2005). MSI1-like proteins: an escort service for chromatin assembly and remodeling complexes. Trends Cell Biol. 15, 295-302. doi: 10.1016/j.tcb.2005.04.004

Hepworth, J., and Dean, C. (2015). Flowering locus C's lessons: conserved chromatin switches underpinning developmental timing and adaptation. Plant Physiol. 168, 1237-1245. doi: 10.1104/pp. 15.00496

Hornyik, C., Terzi, L. C., and Simpson, G. G. (2010). The spen family protein FPA controls alternative cleavage and polyadenylation of RNA. Dev. Cell 18, 203-213. doi: 10.1016/j.devcel.2009.12.009

Huang, D. W., Sherman, B. T., and Lempicki, R. A. (2009). Bioinformatics enrichment tools: paths toward the comprehensive functional analysis of large gene lists. Nucleic Acids Res. 37, 1-13. doi: 10.1093/nar/ gkn923

Jiang, D., Yang, W., He, Y., and Amasino, R. M. (2007). Arabidopsis relatives of the human lysine-specific Demethylase1 repress the expression of FWA and FLOWERING LOCUS C and thus promote the floral transition. Plant Cell 19, 2975-2987. doi: 10.1105/tpc.107.052373

Johanson, U., West, J., Lister, C., Michaels, S., Amasino, R., and Dean, C. (2000). Molecular analysis of FRIGIDA, a major determinant of natural variation in Arabidopsis flowering time. Science 290, 344-347. doi: 10.1126/science.290.5490.344

Kim, H.-J., Hyun, Y., Park, J.-Y., Park, M.-J., Park, M.-K., Kim, M. D., et al. (2004). A genetic link between cold responses and flowering time through FVE in Arabidopsis thaliana. Nat. Genet. 36, 167-171. doi: 10.1038/ ng1298

King, I. F., Emmons, R. B., Francis, N. J., Wild, B., Müller, J., Kingston, R. E., et al. (2005). Analysis of a polycomb group protein defines regions that link repressive activity on nucleosomal templates to in vivo function. Mol. Cell. Biol. 25, 6578-6591. doi: 10.1128/MCB.25.15.6578-6591.2005

Köhler, C., Hennig, L., Bouveret, R., Gheyselinck, J., Grossniklaus, U., and Gruissem, W. (2003). Arabidopsis MSIl is a component of the MEA/FIE Polycomb group complex and required for seed development. EMBO J. 22, 4804-4814. doi: 10.1093/emboj/cdg444

Koornneef, M., Alonso-Blanco, C., Blankestijn-de Vries, H., Hanhart, C., and Peeters, A. (1998). Genetic interactions among late-flowering mutants of Arabidopsis. Genetics 148, 885-892.

Koornneef, M., Hanhart, C., and Van der Veen, J. (1991). A genetic and physiological analysis of late flowering mutants in Arabidopsis thaliana. Mol. Gen. Genet. 229, 57-66. doi: 10.1007/BF00264213

Li, Y., Jones, L., and McQueen-Mason, S. (2003). Expansins and cell growth. Curr. Opin. Plant Biol. 6, 603-610. doi: 10.1016/j.pbi.2003. 09.003

Liu, F., Marquardt, S., Lister, C., Swiezewski, S., and Dean, C. (2010). Targeted processing of antisense transcripts triggers Arabidopsis FLC chromatin silencing. Science 327, 94-97. doi: 10.1126/science.1180278

Liu, F., Quesada, V., Crevillén, P., Bäurle, I., Swiezewski, S., and Dean, C. (2007). The Arabidopsis RNA-binding protein FCA requires a lysine-specific demethylase 1 homolog to downregulate FLC. Mol. Cell 28, 398-407. doi: 10.1016/j.molcel.2007.10.018

Lu, Q., Tang, X., Tian, G., Wang, F., Liu, K., Nguyen, V., et al. (2010). Arabidopsis homolog of the yeast TREX-2 mRNA export complex: components and anchoring nucleoporin. Plant J. 61, 259-270. doi: 10.1111/j.1365313X.2009.04048.x
Luo, M., Tai, R., Yu, C. W., Yang, S., Chen, C., Lin, W. D., et al. (2015). Regulation of flowering time by the histone deacetylase HDA5 in Arabidopsis. Plant J. 82, 925-936. doi: $10.1111 /$ tpj. 12868

Marquardt, S., Raitskin, O., Wu, Z., Liu, F., Sun, Q., and Dean, C. (2014). Functional consequences of splicing of the antisense transcript COOLAIR on FLC transcription. Mol. Cell 54, 156-165. doi: 10.1016/j.molcel.2014. 03.026

Mäser, P., Thomine, S., Schroeder, J. I., Ward, J. M., Hirschi, K., Sze, H., et al. (2001). Phylogenetic relationships within cation transporter families of Arabidopsis. Plant Physiol. 126, 1646-1667. doi: 10.1104/pp.126.4.1646

Michaels, S. D., and Amasino, R. M. (1999). FLOWERING LOCUS C encodes a novel MADS domain protein that acts as a repressor of flowering. Plant Cell 11, 949-956. doi: 10.1105/tpc.11.5.949

Michaels, S. D., and Amasino, R. M. (2001). Loss of FLOWERING LOCUS C activity eliminates the late-flowering phenotype of FRIGIDA and autonomous pathway mutations but not responsiveness to vernalization. Plant Cell 13, 935-941. doi: 10.1105/tpc.13.4.935

Michaels, S. D., He, Y., Scortecci, K. C., and Amasino, R. M. (2003). Attenuation of FLOWERING LOCUS C activity as a mechanism for the evolution of summerannual flowering behavior in Arabidopsis. Proc. Natl. Acad. Sci. U.S.A. 100, 10102-10107. doi: 10.1073/pnas.1531467100

Mortazavi, A., Williams, B. A., McCue, K., Schaeffer, L., and Wold, B. (2008). Mapping and quantifying mammalian transcriptomes by RNA-Seq. Nat. Methods 5, 621-628. doi: 10.1038/nmeth.1226

Mouradov, A., Cremer, F., and Coupland, G. (2002). Control of flowering time interacting pathways as a basis for diversity. Plant Cell 14, S111-S130.

Murfett, J., Wang, X.-J., Hagen, G., and Guilfoyle, T. J. (2001). Identification of Arabidopsis histone deacetylase HDA6 mutants that affect transgene expression. Plant Cell 13, 1047-1061. doi: 10.2307/3871363

Nishitani, K., and Tominaga, R. (1992). Endo-xyloglucan transferase, a novel class of glycosyltransferase that catalyzes transfer of a segment of xyloglucan molecule to another xyloglucan molecule. J. Biol. Chem. 267, 21058-21064.

Pazhouhandeh, M., Molinier, J., Berr, A., and Genschik, P. (2011). MSI4/FVE interacts with CUL4-DDB1 and a PRC2-like complex to control epigenetic regulation of flowering time in Arabidopsis. Proc. Natl. Acad. Sci. U.S.A. 108, 3430-3435. doi: 10.1073/pnas. 1018242108

Severin, A. J., Woody, J. L., Bolon, Y.-T., Joseph, B., Diers, B. W., Farmer, A. D., et al. (2010). RNA-Seq Atlas of Glycine max: a guide to the soybean transcriptome. BMC Plant Biol. 10:160. doi: 10.1186/1471-2229-10-160

Sheldon, C. C., Burn, J. E., Perez, P. P., Metzger, J., Edwards, J. A., Peacock, W. J., et al. (1999). The FLF MADS box gene: a repressor of flowering in Arabidopsis regulated by vernalization and methylation. Plant Cell 11, 445-458. doi: 10.1105/tpc.11.3.445

Simpson, G. G. (2004). The autonomous pathway: epigenetic and posttranscriptional gene regulation in the control of Arabidopsis flowering time. Curr. Opin. Plant Biol. 7, 570-574. doi: 10.1016/j.pbi.2004. 07.002

Smith, T. F., Gaitatzes, C., Saxena, K., and Neer, E. J. (1999). The WD repeat: a common architecture for diverse functions. Trends Biochem. Sci. 24, 181-185. doi: 10.1016/S0968-0004(99)01384-5

Spartz, A. K., Ren, H., Park, M. Y., Grandt, K. N., Lee, S. H., Murphy, A. S., et al. (2014). SAUR inhibition of PP2C-D phosphatases activates plasma membrane H+-ATPases to promote cell expansion in Arabidopsis. Plant Cell 26, 2129 2142. doi: $10.1105 /$ tpc. 114.126037

Streitner, C., Danisman, S., Wehrle, F., Schöning, J. C., Alfano, J. R., and Staiger, D. (2008). The small glycine-rich RNA binding protein AtGRP7 promotes floral transition in Arabidopsis thaliana. Plant J. 56, 239-250. doi: 10.1111/j.1365313X.2008.03591.x

Sung, S., and Amasino, R. M. (2004). Vernalization in Arabidopsis thaliana is mediated by the PHD finger protein VIN3. Nature 427, 159-164. doi: 10.1038 /nature02195

Sung, S., Schmitz, R. J., and Amasino, R. M. (2006). A PHD finger protein involved in both the vernalization and photoperiod pathways in Arabidopsis. Genes Dev. 20, 3244-3248. doi: 10.1101/gad.1493306

Tie, F., Furuyama, T., Prasad-Sinha, J., Jane, E., and Harte, P. J. (2001). The Drosophila Polycomb Group proteins ESC and E (Z) are present in a complex containing the histone-binding protein p55 and the histone deacetylase RPD3. Development 128, 275-286. 
Van Nocker, S., and Ludwig, P. (2003). The WD-repeat protein superfamily in Arabidopsis: conservation and divergence in structure and function. BMC Genomics 4:50. doi: 10.1186/1471-2164-4-50

Van Sandt, V. S., Suslov, D., Verbelen, J.-P., and Vissenberg, K. (2007). Xyloglucan endotransglucosylase activity loosens a plant cell wall. Ann. Bot. 100, $1467-$ 1473. doi: $10.1093 / \mathrm{aob} / \mathrm{mcm} 248$

Vermaak, D., Wade, P. A., Jones, P. L., Shi, Y.-B., and Wolffe, A. P. (1999). Functional analysis of the SIN3-histone deacetylase RPD3-RbAp48-histone H4 connection in the Xenopus oocyte. Mol. Cell. Biol. 19, 5847-5860. doi: 10.1128/MCB.19.9.5847

Wang, C., Tian, Q., Hou, Z., Mucha, M., Aukerman, M., and Olsen, O. A. (2007). The Arabidopsis thaliana AT PRP39-1 gene, encoding a tetratricopeptide repeat protein with similarity to the yeast premRNA processing protein PRP39, affects flowering time. Plant Cell Rep. 26, 1357-1366. doi: 10.1007/s00299-007-0336-5

Wang, Z.-W., Wu, Z., Raitskin, O., Sun, Q., and Dean, C. (2014). Antisensemediated FLC transcriptional repression requires the $\mathrm{P}-\mathrm{TEFb}$ transcription elongation factor. Proc. Natl. Acad. Sci. U.S.A. 111, 7468-7473. doi: 10.1073/pnas.1406635111

Yadav, V., Molina, I., Ranathunge, K., Castillo, I. Q., Rothstein, S. J., and Reed, J. W. (2014). ABCG transporters are required for suberin and pollen wall extracellular barriers in Arabidopsis. Plant Cell 26, 3569-3588. doi: 10.1105/tpc.114.129049
Yang, D.-H., Maeng, S., and Bahn, Y.-S. (2013). Msi1-like (MSIL) proteins in fungi. Mycobiology 41, 1-12. doi: 10.5941/MYCO.2013.41.1.1

Yu, C.-W., Liu, X., Luo, M., Chen, C., Lin, X., Tian, G., et al. (2011). HISTONE DEACETYLASE6 interacts with FLOWERING LOCUS D and regulates flowering in Arabidopsis. Plant Physiol. 156, 173-184. doi: 10.1104/pp.111.174417

Zhu, Z., An, F., Feng, Y., Li, P., Xue, L., Mu, A., et al. (2011). Derepression of ethylene-stabilized transcription factors (EIN3/EIL1) mediates jasmonate and ethylene signaling synergy in Arabidopsis. Proc. Natl. Acad. Sci. U.S.A. 108, 12539-12544. doi: 10.1073/pnas.11039 59108

Conflict of Interest Statement: The authors declare that the research was conducted in the absence of any commercial or financial relationships that could be construed as a potential conflict of interest.

Copyright (c) $2016 \mathrm{Yu}$, Chang and Wu. This is an open-access article distributed under the terms of the Creative Commons Attribution License (CC BY). The use, distribution or reproduction in other forums is permitted, provided the original author(s) or licensor are credited and that the original publication in this journal is cited, in accordance with accepted academic practice. No use, distribution or reproduction is permitted which does not comply with these terms. 